\title{
Article
}

\section{Reactive Distillation for Two-Stage Reaction Systems: Adipic Acid and Glutaric Acid Esterifications}

Shih-Bo Hung, I-Kuan Lai, Hsiao-Ping Huang, Ming-Jer Lee, and Cheng-Ching Yu

Ind. Eng. Chem. Res., 2008, 47 (9), 3076-3087 • DOI: 10.1021/ie070609+

Downloaded from http://pubs.acs.org on November 18, 2008

\section{More About This Article}

Additional resources and features associated with this article are available within the HTML version:

- $\quad$ Supporting Information

- $\quad$ Access to high resolution figures

- $\quad$ Links to articles and content related to this article

- $\quad$ Copyright permission to reproduce figures and/or text from this article

\section{View the Full Text HTML}




\title{
Reactive Distillation for Two-Stage Reaction Systems: Adipic Acid and Glutaric Acid Esterifications
}

\author{
Shih-Bo Hung, ${ }^{\dagger}$ I-Kuan Lai, ${ }^{\ddagger}$ Hsiao-Ping Huang,,${ }^{\dagger}$ Ming-Jer Lee, ${ }^{\dagger}$ and Cheng-Ching $\mathbf{Y u}^{*, \downarrow}$ \\ Departments of Chemical Engineering, National Taiwan University, Taipei 106-17, Taiwan, and National \\ Taiwan University of Science and Technology, Taipei 106-07, Taiwan
}

\begin{abstract}
Two new complete reactive distillation processes for two-stage reaction systems (adipic acid and glutaric acid esterifications with methanol) are explored. Similarities and differences between these two flowsheets have been identified. Both the diacid esterification reactions are catalyzed heterogeneously by an acidic ionexchange resin, and reaction kinetics can be described using quasihomogeneous model. The UNIFAC method predicts suitable NRTL parameters for calculating liquid activity coefficients, which give a good description of experimental data. Results show that the plantwide flowsheets need a large recycle ratio for the light key reactants and ester products could be achieved with a purity of $99 \mathrm{~mol} \%$. A systematic design procedure for the complete flowsheets is presented, and the optimum operating conditions of the overall systems are studied to minimize the total annual cost while meeting the product specifications.
\end{abstract}

\section{Introduction}

Reactive distillation (RD) combines reaction and separation in a single unit and provides substantial economic benefit for some chemical processes. RD provides an attractive alternative for process intensification, especially for reaction/separation systems with reversible reactions. The books by Doherty and Malone $^{1}$ and Sundmacher and Kienle ${ }^{2}$ give updated summaries of the field. Taylor and Krishna ${ }^{3}$ describe potential advantages, modeling, simulation, and hardware configurations of reactive distillation. In the book by Sundmacher and Kienle, ${ }^{2}$ there is a comprehensive list of the reactions that have been investigated as candidates for $\mathrm{RD}$. According to the list collected, we may find that most of the industrial applications of RD may be divided into three reaction types: (A) simple reversible reaction, (B) parallel reactions, and (C) two-stage cascade reactions.

Type A and type B are two more common types applied in that the main applications for RD processes are etherification and esterification. A significant portion of the literature is devoted to esterification of acetic acid processes for which the reaction can be simply described as acid + alcohol $\leftrightarrow$ acetate + water. $^{4-7}$ Although the reaction mechanism seems to be quite simple, the process design varies greatly for the different cases. $\mathrm{Tang}^{8}$ et al. explored the applicable reactive distillation configurations for acetic acid esterification with different alcohols (ranging from $\mathrm{C} 1$ to $\mathrm{C} 5$ ) and provided systematic design procedures. The etherification is a notable example that is representative of type $\mathrm{B}$, such as the production of MTBE or TAME. ${ }^{9,10}$ Both reactions can be described as methanol + iso-olefin (isobutene/isoamylene) $\leftrightarrow$ tert-ether (MTBE/TAME) and usually carried out in the presence of impurity for side reactions (1-butene in MTBE and n-pentene in TAME). Only a limited number of papers discuss the two-stage (type $\mathrm{C}$ ) reaction in $\mathrm{RD}$ systems. A typical example is the reaction with the following form: $\mathrm{A}+\mathrm{B} \leftrightarrow \mathrm{C}+\mathrm{D}, \mathrm{B}+\mathrm{C} \leftrightarrow \mathrm{D}+\mathrm{E}$ ). Ung and Doherty ${ }^{11,12}$ identified the feasible regions of

* Corresponding author. Tel.: +886-2-3366-3037. Fax: +886-22362-3040. E-mail: ccyu@ntu.edu.tw.

National Taiwan University of Science and Technology.

$¥$ National Taiwan University. product compositions for this type on the basis of phase and reaction equilibria. Luo and $\mathrm{Xiao}^{13}$ studied the transesterification of dimethyl carbonate (DMC) and ethanol with methyl ethyl carbonate as an intermediate and the performance of different reactive distillation designs using rigorous steady-state simulation. There is another esterification type belonging to type $\mathrm{C}$ that has received little attention so far: a two-stage cascade esterification. An example follows: If a diacid is esterified with a monoalcohol, a monoester will be produced at the first stage and will simultaneously react with the alcohol to form a diester.

In this work, we explore two alternative RD flowsheets for diacid esterification processes. The conceptual design is based on the physical and thermodynamic properties of the system, and total annual cost (TAC) is used to evaluate the appropriateness of different designs. We use dimethyl adipate as the primary case study illustration, and compare it with dimethyl glutarate in section 6. Dimethyl adipate (DMA) is used as part of a dibasic ester (DBE) blend that is used as a major ingredient in several paint strippers. The DMA content in DBE blends varies from about $15 \%$ to $90 \%$. The other components of the DBE blends are dimethyl glutarate (DMG) and dimethyl succinate (DMS). It is worthwhile to note that DBE has the advantages of very low toxicity, great stability, rather high boiling point, and viscosity and density that are close to water.

The paper is organized as follows. Section 2 describes the reaction kinetics of the adipic acid esterification. The physical properties and thermodynamic behaviors of DMA system are explored in section 3. On the basis of the thermodynamic analyses, two possible flowsheets are generated, and improved designs are sought by minimizing the TAC. Next, comparisons between these two flowsheets are made. Section 6 extends the design to dimethyl glutarate production. In this work, the design is carried out using Aspen Plus.

\section{Reaction Kinetics}

The esterification of adipic acid (AA) and methanol (MeOH) proceeds by two reversible cascade reactions with adipic acid monomethyl ester (monomethyl adipate, MMA) as an intermediate: 


$$
\begin{gathered}
\mathrm{AA}+\mathrm{MeOH} \underset{k_{-1}}{\stackrel{k_{1}}{\rightleftharpoons}} \mathrm{MMA}+\mathrm{H}_{2} \mathrm{O} \\
\mathrm{MMA}+\mathrm{MeOH} \underset{k_{-2}}{\stackrel{k_{2}}{\rightleftharpoons}} \mathrm{DMA}+\mathrm{H}_{2} \mathrm{O}
\end{gathered}
$$

The kinetics data and rate expressions are taken from the experimental work of Chan. ${ }^{14}$ In Chan's work, Amberlyst 15 (Rohm and Hass) acidic ion-exchange resin was used as a solid catalyst, and quasihomogeneous models could quite appropriately describe the reaction mechanisms. The reaction rate expressions are as follows:

$$
\begin{aligned}
& \frac{-\mathrm{d} C_{\mathrm{AA}}}{\mathrm{d} t}=k_{1} C_{\mathrm{AA}} C_{\mathrm{MeOH}}-k_{-1} C_{\mathrm{MMA}} C_{\mathrm{H}_{2} \mathrm{O}} \\
& \frac{-\mathrm{d} C_{\mathrm{MeOH}}}{\mathrm{d} t}=k_{1} C_{\mathrm{AA}} C_{\mathrm{MeOH}}-k_{-1} C_{\mathrm{MMA}} C_{\mathrm{H}_{2} \mathrm{O}}+ \\
& k_{2} C_{\mathrm{MMA}} C_{\mathrm{MeOH}}-k_{-2} C_{\mathrm{DMA}} C_{\mathrm{H}_{2} \mathrm{O}} \\
& \frac{\mathrm{dC}_{\mathrm{MMA}}}{\mathrm{d} t}=k_{1} C_{\mathrm{AA}} C_{\mathrm{MeOH}}-k_{-1} C_{\mathrm{MMA}} C_{\mathrm{H}_{2} \mathrm{O}}- \\
& k_{2} C_{\mathrm{MMA}} C_{\mathrm{MeOH}}+k_{-2} C_{\mathrm{DMA}} C_{\mathrm{H}_{2} \mathrm{O}} \\
& \frac{\mathrm{dC}_{\mathrm{H}_{2} \mathrm{O}}}{\mathrm{d} t}=k_{1} C_{\mathrm{AA}} C_{\mathrm{MeOH}}-k_{-1} C_{\mathrm{MMA}} C_{\mathrm{H}_{2} \mathrm{O}}+ \\
& k_{2} C_{\mathrm{MMA}} C_{\mathrm{MeOH}}-k_{-2} C_{\mathrm{DMA}_{2}} C_{\mathrm{H}_{2} \mathrm{O}} \\
& \frac{\mathrm{dC}_{\mathrm{DMA}}}{\mathrm{d} t}=k_{2} C_{\mathrm{MMA}} C_{\mathrm{MeOH}}-k_{-2} C_{\mathrm{DMA}} C_{\mathrm{H}_{2} \mathrm{O}}
\end{aligned}
$$

where $C_{i}$ represents the molar concentrations $\left(\mathrm{mol} / \mathrm{cm}^{3}\right)$ of component $i$, and the forward reaction rate constants $\left(\mathrm{cm}^{6} / \mathrm{g}\right.$ cat/ $\mathrm{min} / \mathrm{mol}$ ) can be expressed as

$$
\begin{aligned}
& k_{1}=5.857 \times 10^{6} \exp \left(\frac{-4097.8}{T}\right) \\
& k_{2}=2.024 \times 10^{6} \exp \left(\frac{-4201.1}{T}\right)
\end{aligned}
$$

Because of negligible heat effects, the equilibrium constants are regarded as temperature independent; thus, we have

$$
\begin{gathered}
K_{\text {leq }}=\frac{k_{1}}{k_{-1}}=0.997 \\
K_{2 \mathrm{eq}}=\frac{k_{2}}{k_{-2}}=2.56
\end{gathered}
$$

In applying the reaction kinetics to reactive distillation, it is assumed that the solid catalyst occupies $50 \%$ of the tray holdup volume and a catalyst density of $800 \mathrm{~kg} / \mathrm{m}^{3}$ is used to convert the volume into catalyst weight $\left(m_{\text {cat }}\right)$.

\section{Thermodynamics}

3.1. Vapor Pressure. Aspen Plus has a built-in data bank with the pure components properties for water, $\mathrm{MeOH}$, and $\mathrm{AA}$, but it lacks data for the two esters, dimethyl adipate and monomethyl adipate. DMA and MMA have very low volatility; thus, the boiling point data are only available under very low pressure from the following data bank: NIST Chemistry WebBook June 2005 Release, http://webbook.nist.gov/chemistry/. In order to obtain the correct saturated vapor pressures of DMA, we take the experimental data ${ }^{15}$ and make new correla- tions. However, MMA has an even lower vapor pressure than DMA, and it is difficult to obtain reliable data for correlation. Therefore, we use MMA's Antonie coefficients of DECHEMA (http://www.dechema.de/). The extended Antoine equation is used, and parameters are given in appendix A. On the basis of vapor pressure models, we have the following normal boiling point ranking for these five components:

$$
\begin{gathered}
\text { AA }\left(337.47{ }^{\circ} \mathrm{C}\right)>\operatorname{MMA}\left(261.76{ }^{\circ} \mathrm{C}\right)> \\
\operatorname{DMA}\left(235.68{ }^{\circ} \mathrm{C}\right)>\mathrm{H}_{2} \mathrm{O}\left(100.0{ }^{\circ} \mathrm{C}\right)> \\
\operatorname{MeOH}\left(64.53{ }^{\circ} \mathrm{C}\right)
\end{gathered}
$$

Unfortunately, the two products (DMA and $\mathrm{H}_{2} \mathrm{O}$ ) are intermediate boilers whereas the reactants are the lowest and highest boilers, respectively. This is the worst case scenario for a reactive distillation.

3.2. Phase Equilibrium. The NRTL-HOC thermodynamic model is used to describe vapor-liquid equilibrium with liquid activity coefficients calculated by the nonrandom two-liquid (NRTL) model, and the vapor association was determined using the method of Hayden and O'Connel ${ }^{16}$ (HOC). The Aspen Plus built-in parameters are employed to compute fugacity coefficients. For activity coefficient, $\mathrm{H}_{2} \mathrm{O}-\mathrm{MeOH}$ is the only pair that has the built-in parameter in Aspen Plus. The UNIFAC ${ }^{17}$ group contribution method is used to estimate the remaining parameters. The predicted results are also verified with the experimental data. ${ }^{15}$ The results show that the estimated parameters give reasonable predictions. Figure 1 shows the VLE (X-Y diagram) for all ten binary pairs. Figure 1a indicated that the relative volatility between $\mathrm{AA}$ and $\mathrm{MeOH}$ is quite large, and that implies it will be difficult to achieve good liquidliquid contact between $\mathrm{AA}$ and $\mathrm{MeOH}$. Since the reaction is carried out in the liquid phase, the "neat" (that is, no excess reactant) flowsheet is impossible. Methanol must be in great excess to ensure adequate liquid contact. For liquid-liquid equilibrium (LLE) calculation, in order to obtain improved accuracy, the NRTL parameter set ${ }^{18}$ is used. The residue curve maps and the liquid-liquid envelopes for all ternary subsystems are shown in Figure 2. There exists a large two-liquid region, e.g., Figure 2c, that can be used for liquid-liquid separation. On the basis of the UNIFAC estimation, the system has only one binary azeotrope (water/DMA, 98.94/1.06 mol \%), at a temperature of $99.77^{\circ} \mathrm{C}$. The azeotrope also locates in a twophase zone, and more importantly, it corresponds to almost pure water. Since the azeotrope is predicted from estimated parameters, regardless of its existence, high purity water can be obtained via liquid-liquid separation. Appendix A gives all parameters for the vapor pressure and VLE and LLE correlations. The conceptual design will be explored next.

\section{Process Flowsheet and Steady-State Design}

4.1. Possible Configurations of Reactive Distillation Column (RDC). According to the normal boiling point ranking (eq 7), the products, DMA and water, are intermediate boilers, while the two reactants are the lightest $(\mathrm{MeOH})$ and heaviest (AA) components. Thus, the removal of the products can be a problem, and the drastically different boiling points of the reactants make the liquid-liquid contact difficult. This implies that one-pass conversion can be very small. Tung and $\mathrm{Yu}^{19}$ discuss the effects of relative volatility ranking on the design of reactive distillation columns. They treated the ideal quaternary system with reversible reaction, $\mathrm{A}+\mathrm{B} \leftrightarrow \mathrm{C}+\mathrm{D}$, and explored optimal flowsheet design based on the total annual cost (TAC). In one of the types they identified, type $\mathrm{I}_{\mathrm{r}}, \mathrm{LLK}+\mathrm{HHK}=\mathrm{LK}$ 
(a)

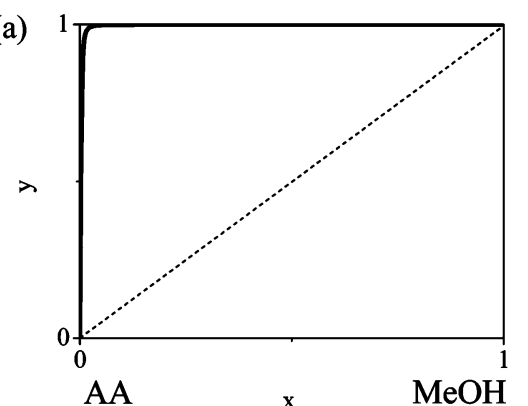

(c)

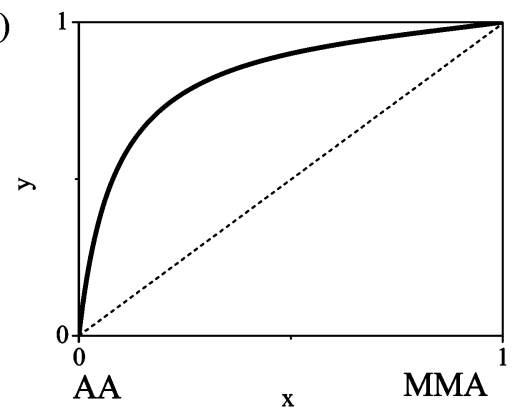

(e)

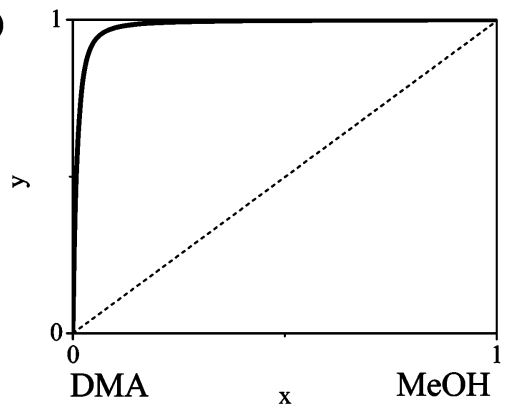

(g)

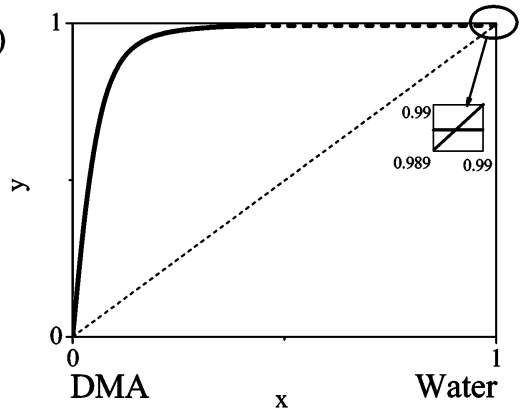

(i)

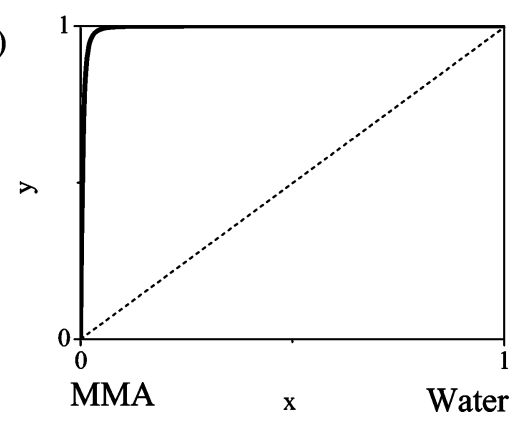

(b)

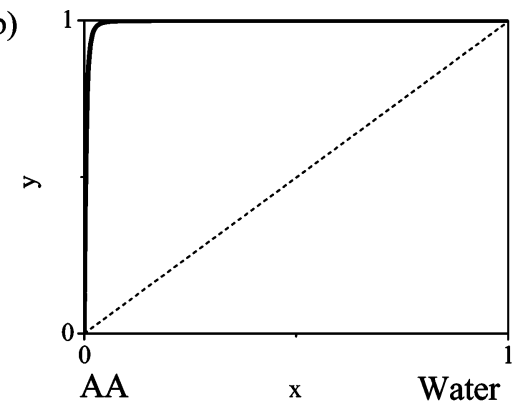

(d)

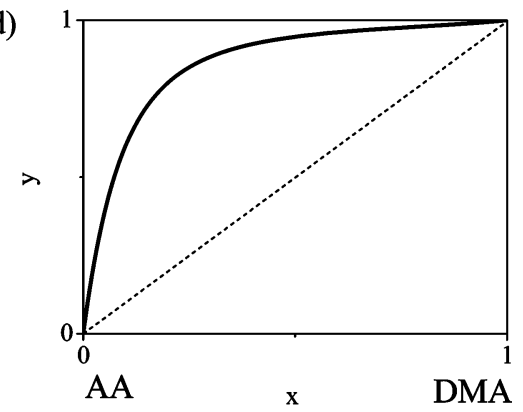

(f)

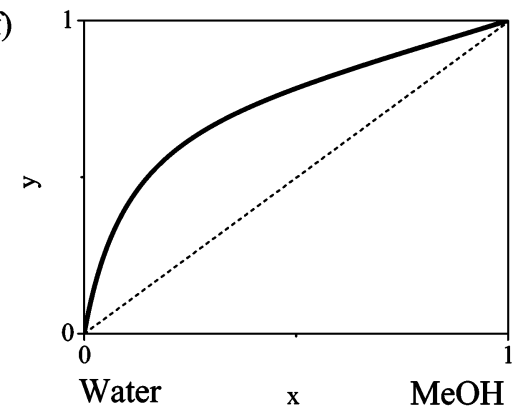

(h)

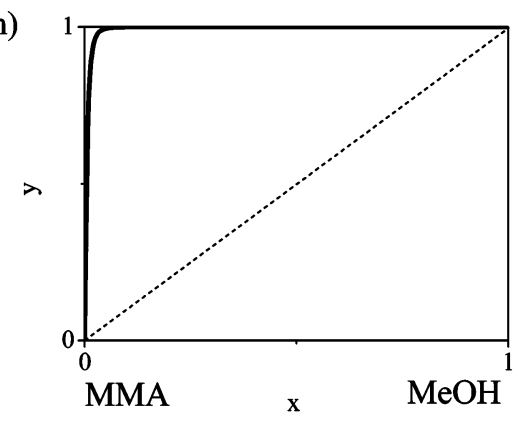

(j)

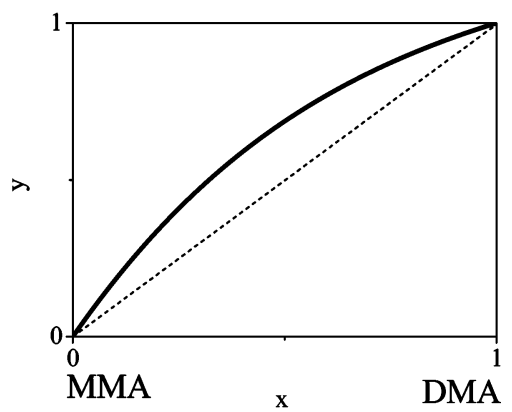

Figure 1. VLE diagrams for (a) adipic acid + methanol, (b) adipic acid + water, (c) adipic acid + monomethyl adipate, (d) adipic acid + dimethyl adipate, (e) dimethyl adipate + methanol, (f) water + methanol, (g) dimethyl adipate + water, (h) monomethyl adipate + methanol, (i) monomethyl adipate + water, and (j) monomethyl adipate + dimethyl adipate.

+ HK, which means the two reactants are lighter than light key component (LLK) A and heavier than heavy key component (HHK) B with the two products being light key component (LK) $\mathrm{C}$ and heavy key component (HK) D. According to the possible $\mathrm{RDC}$ configuration of this type by Tung and $\mathrm{Yu},{ }^{19}$ the reactive zones are placed at the opposite ends of the column where significant amounts of LLK and HHK (two reactants) are present (Figure 3, left part). The fresh heavy reactant (HHK) is introduced into the top of the column where a significant amount of the other reactant (LLK) is most abundant. Similarly, the 
(a)

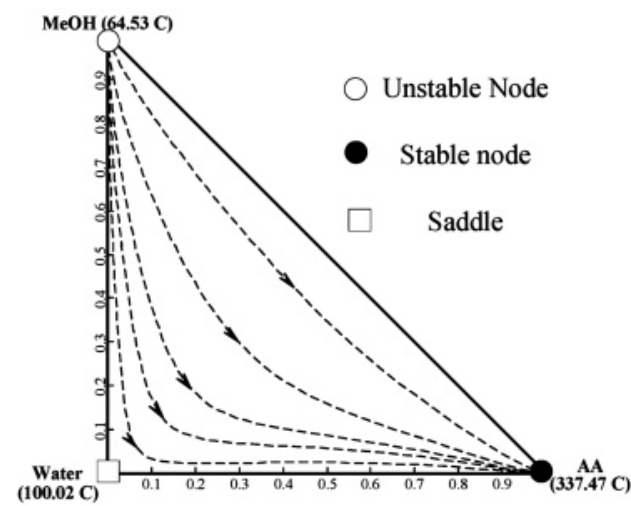

(c)

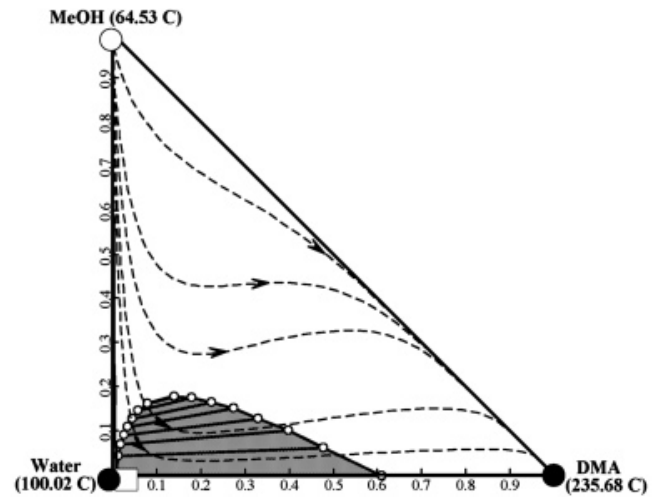

(b)

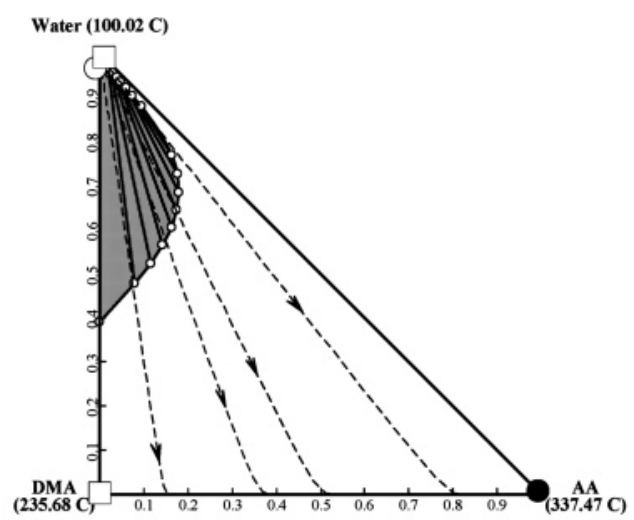

(d)

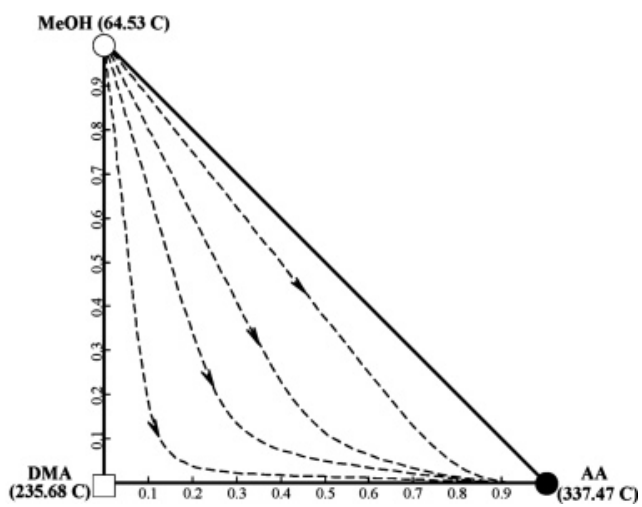

Figure 2. Ternary residual curve maps and two-liquid zone for methanol, adipic acid, dimethyl adipate, and water system at $P=1$ atm.

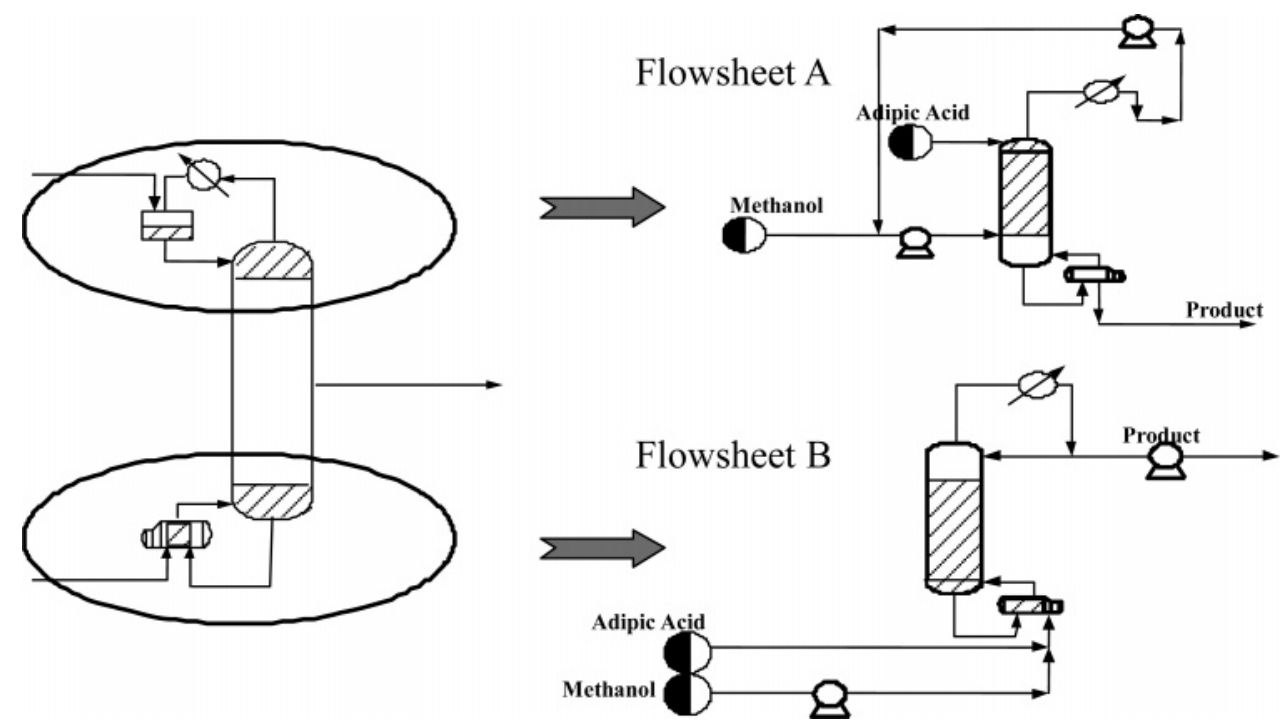

Figure 3. Two alternative reactive distillation configurations for excess reactant design.

fresh light reactant (LLK) is fed to the bottom of the column, where a significant amount of the heavy reactant (HHK) is present. Products are withdrawn from the midsection of the column as a side stream, and a product column is used to separate these two products. Considering the net adipic acid esterification, it also can be expressed as

$$
\underset{\text { LLK }}{2 \mathrm{MeOH}}+\underset{\mathrm{HHK}}{\operatorname{adipic} \text { acid }} \rightarrow \underset{\mathrm{LK}}{2 \mathrm{H}_{2} \mathrm{O}}+\underset{\text { dimethyl adipate }}{\mathrm{HK}}
$$

The boiling point ranking is exactly the same as that of type $I_{r}$, but again, the "neat" operation is not likely. The reason is the large relative volatility between the two reactants, and in fact, the normal boiling temperature difference is about $270{ }^{\circ} \mathrm{C}$ at atmospheric pressure. Figure 3 also shows two possible "excess reactant" designs. The first configuration is placing the reactive zone at the upper section of a reactive distillation column, flowsheet $\mathrm{A}$ in Figure 3, where the light reactant (methanol) is introduced to the lower end of the reactive zone while the heavy reactant (adipic acid) is fed from the column top. With light reactant in excess, the unreacted methanol is withdrawn from the top and recycled back to the RD column. The other alternative is to place the reactive zone in the lower section of 


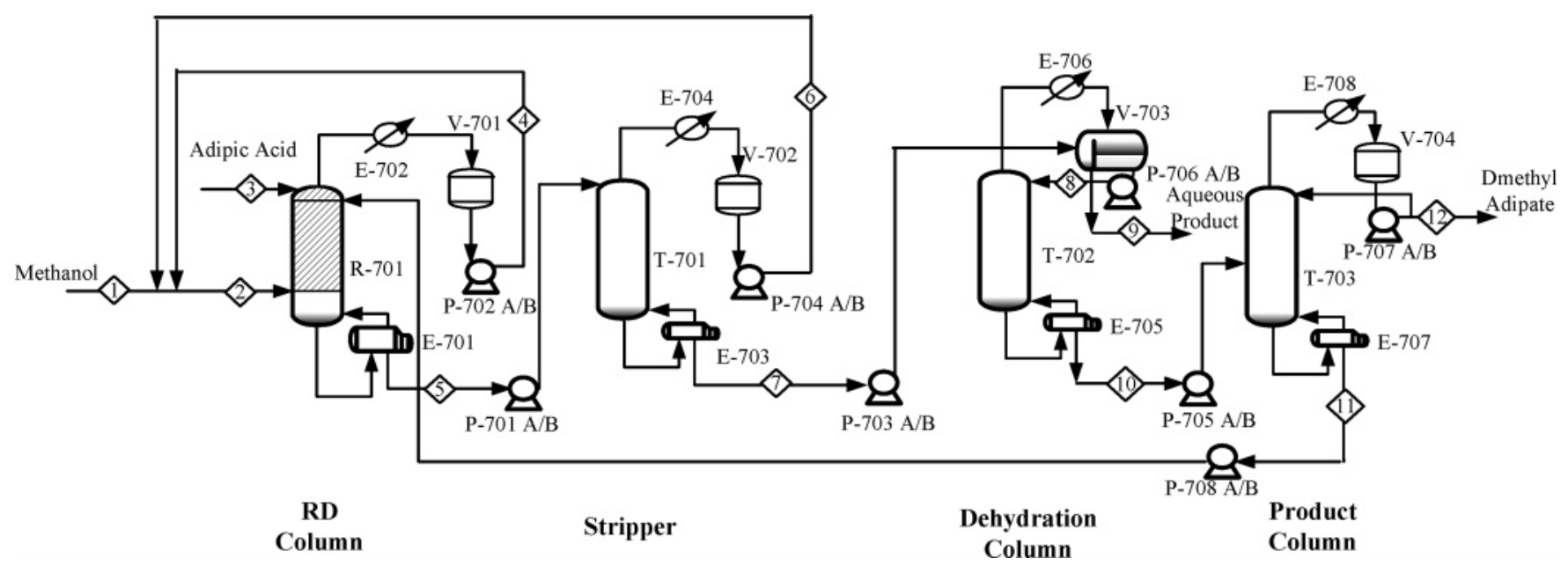

Figure 4. Flowsheet A for dimethyl adipate production.

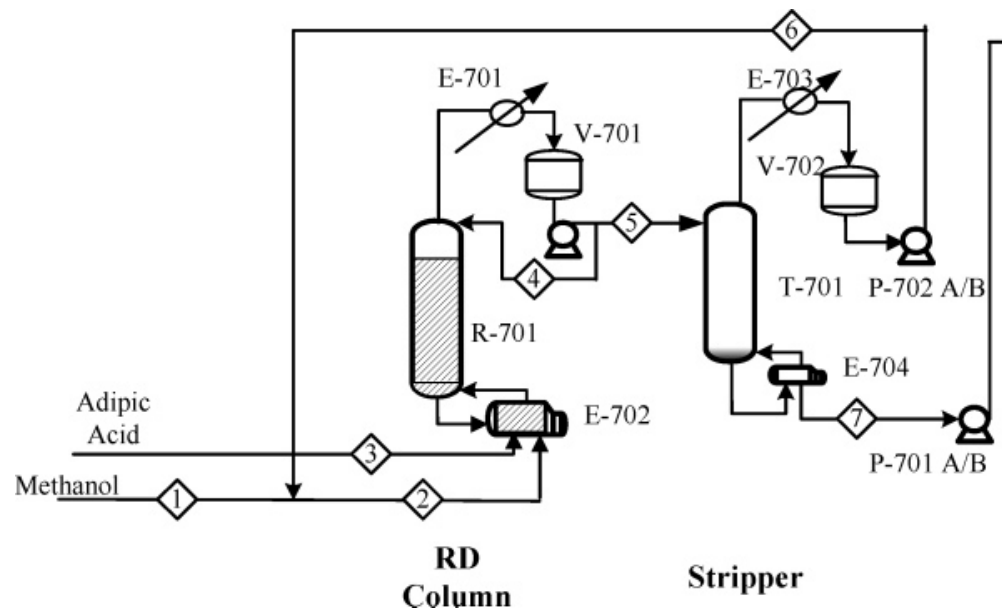

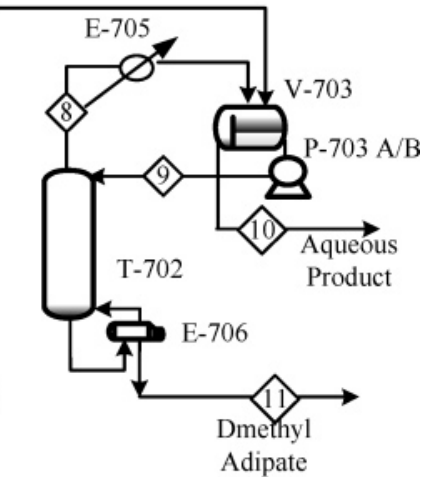

Product Column
Figure 5. Flowsheet B for dimethyl adipate production.

a RD column, flowsheet B in Figure 3. Both reactants are fed into the column base, and the excess reactant (methanol) as well as products are removed from the overhead of the column. Note that there is no outlet at the bottom, and the configuration is quite similar to that for ethyl acetate production, ${ }^{8}$ except for "excess" reactant design.

4.2. Complete Flowsheet. Because of the "excess" reactant design and multiple product nature, recycle column and product columns are necessary to complete the design of the entire plant. In this section, two flowsheets are devised for the production of high purity diester. As will be explained later, the placement of the reactant zone and the location for the withdrawal of the products result in different selectivities for these two flowsheets. Thus, the design for subsequent separation sections will be different.

4.2.1. Flowsheet A. Flowsheet A (FSA) is based on the RD column where the reactive zone is placed at the top (Figure 3). Because the intermediate product (MMA) is heavier than the main product (DMA), the selectivity is a little greater than $98 \%$, e.g., 98.6\%. Thus, MMA has to be recovered and recycled back to the RD. Figure 4 shows the complete process flowsheet. Because the light reactant (methanol) is much lighter than the product, the reactive distillation column is configured as a stripper, i.e., no condenser, and the lights, mostly methanol with some water, go out from the top of the reactive stripper. The overhead vapor, stream 4 , is made of $80 \%$ methanol and $20 \%$ water, which is recycled and mixed with the fresh feed (stream 2) and then is fed into the lower section of the reactive zone. Because the limiting reactant, adipic acid, is near a complete conversion, the bottoms flow, stream 5, of the reactive stripper is made of excess lights ( $\mathrm{MeOH}$ and water) and heavy product and byproduct (DMA and MMA). In the separation section, a stripper (Figure 4, T-701) is used to prevent methanol leaving the system, and the overhead stream (stream 6) of the stripper is also recycled back to the reactive stripper. Thus, the major components in the stripper bottoms flow, stream 7, are water and DMA with a small amount of MMA. Because a tie line connects to the pure water node for the water-DMA pair (Figure 2), this stream is fed into the overhead decanter (Figure 2, V-703) of a dehydration column (Figure 4, V-703). Water is removed from the decanter while the organic phase is recycled back to the dehydration column, and the bottoms flow consists of mostly MMA and DMA. Finally, a product column (Figure 4, T-703) separates these two esters. High purity DMA is withdrawn from the top while the byproduct, MMA, is recycled back to the top reactive tray of the reactive stripper.

4.2.2. Flowsheet B. Flowsheet B (FSB) is based on the configuration where the reactive zone is placed at the lower section of the column and all the products and excess reactant are taken out from the column top. Unlike that in flowsheet A, the heavier intermediate product (MMA) is trapped in the reactive zone while the relatively light product (DMA) leaves the column with a trace amount of MMA. Thus, the selectivity is near $100 \%$. Figure 5 shows the entire plant of the flowsheet B. The distillate (stream 5) of the RD is fed into the methanol recovery separator, a stripper (Figure 5, T-701), where most of the excess methanol is recovered. The bottom of the stripper (stream 7) is then fed into the decanter of the product column 
Table 1. Results of Steady-State Designs of DMA System (Two Flowsheets) and DMG System

\begin{tabular}{|c|c|c|c|}
\hline case & $\begin{array}{l}\text { DMA } \\
\text { (FSA) }\end{array}$ & $\begin{array}{l}\text { DMA(FSB) } \\
\text { (DMA) }\end{array}$ & DMG \\
\hline $\begin{array}{l}\text { total no. of trays including the } \\
\text { reboiler in RD column }\end{array}$ & 75 & 21 & 21 \\
\hline no. of trays in stripping section $\left(N_{\mathrm{S}}\right)$ & 5 & 0 & 0 \\
\hline no. of trays in reactive section $\left(N_{\mathrm{rxn}}\right)$ & 70 & 13 & 12 \\
\hline no. of trays in rectifying section $\left(N_{\mathrm{R}}\right)$ & 0 & 8 & 9 \\
\hline reactive tray & $5-75$ & $0-13$ & $0-11$ \\
\hline RD column diameter $(\mathrm{m})$ & 1.156 & 1.141 & 0.72 \\
\hline $\mathrm{RD}$ column reboiler duty $(\mathrm{kW})$ & 2479.85 & 2198.69 & 716.62 \\
\hline $\begin{array}{l}\text { total no. of trays including the } \\
\text { reboiler in stripper }\left(N_{\mathrm{STR}}\right)\end{array}$ & 11 & 14 & \\
\hline stripper diameter $(\mathrm{m})$ & 0.83 & 0.912 & \\
\hline stripper reboiler duty $(\mathrm{kW})$ & 1185.31 & 1505.4 & \\
\hline $\begin{array}{l}\text { total no. of trays including the } \\
\text { reboiler in dehydration column } \\
\left(N_{\text {DHC }}\right)\end{array}$ & 4 & & \\
\hline dehydration column diameter (m) & 0.576 & & \\
\hline $\begin{array}{l}\text { dehydration column reboiler duty } \\
\text { (kW) }\end{array}$ & 268.59 & & \\
\hline $\begin{array}{l}\text { total no. of trays including the reboiler } \\
\text { in methanol recovery column } \\
\left(N_{\mathrm{MRC}}\right)\end{array}$ & & & 22 \\
\hline feed tray of methanol recovery column & & & 15 \\
\hline $\begin{array}{l}\text { methanol recovery column diameter } \\
(\mathrm{m})\end{array}$ & & & 0.611 \\
\hline $\begin{array}{l}\text { methanol recovery column reboiler } \\
\text { duty }(\mathrm{kW})\end{array}$ & & & 746.73 \\
\hline $\begin{array}{l}\text { total no. of trays including the reboiler } \\
\text { in product column }\end{array}$ & 21 & 3 & 3 \\
\hline product column diameter $(\mathrm{m})$ & 0.51 & 0.202 & 0.297 \\
\hline product column reboiler duty $(\mathrm{kW})$ & 200.63 & 183.48 & 212.91 \\
\hline decanter duty (kW) & -67.69 & -62.45 & -73.64 \\
\hline adipic acid feed tray & 75 & 0 & \\
\hline glutaric acid feed tray & & & 0 \\
\hline methanol feed tray & 5 & 0 & 0 \\
\hline ital cost $) / 3(\$ 1000)$ & 632.33 & 392.04 & 275.38 \\
\hline RD column & 395.3 & 201.77 & 112.3 \\
\hline stripper or methanol recovery column & 129.86 & 156.92 & 119.2 \\
\hline dehydration column (include decanter) & 49.42 & & \\
\hline product column (include decanter) & 57.75 & 33.3 & 43.88 \\
\hline total operating cost ( $\$ 1000 /$ year) & 430.784 & 495.805 & 134.0 \\
\hline catalyst cost & 82.8 & 48.5 & 4.6 \\
\hline energy cost & 347.984 & 447.305 & 129.4 \\
\hline TAC $(\$ 1000 /$ year $)(10 \mathrm{kmol} / \mathrm{hr})$ & 1063.114 & 887.845 & 409.38 \\
\hline
\end{tabular}

(Figure 5, T-702) with less than $0.1 \%$ of methanol as impurity. Water (stream 10) is withdrawn from the decanter as a result of a significant two-liquid zone between water and DMA. High purity DMA is obtained from the column base (stream 11) because of easy separation between these two components. It is clear that the difference between flowsheet A and B lies in the fact that flowsheet B possesses a much better selectivity, as a result of the placement of the reactive zone. Therefore, compared with FSA, this flowsheet requires one fewercolumn.

4.3. Design Procedure. Once the conceptual design is completed, a systematic procedure is devised to achieve an improved design to reduce the TAC. The main design parameters for these two flowsheets are tray numbers of individual columns. Flowsheet A consists of a reactive stripper with an upper section reactive section $\left(N_{\mathrm{rxn}, \mathrm{A}}\right)$ and a stripping separation section $\left(N_{\mathrm{S}, \mathrm{A}}\right)$, a stripper $\left(N_{\mathrm{STR}, \mathrm{A}}\right)$, a dehydration column $\left(N_{\mathrm{DHC}}\right)$, and a product column $\left(N_{\text {PROD,A }}\right)$. Similarly, flowsheet B consists of a reactive distillation column with a lower reactive zone $\left(N_{\mathrm{rxn}, \mathrm{B}}\right)$ and a rectifying section $\left(N_{\mathrm{R}, \mathrm{B}}\right)$, a stripper $\left(N_{\mathrm{STR}, \mathrm{B}}\right)$, and a product column $\left(N_{\mathrm{PROD}, \mathrm{B}}\right)$. We assume the production rate of DMA is $10 \mathrm{kmol} / \mathrm{h}$ with a product purity of $99 \mathrm{~mol} \%$. The fresh feed flow rates of both reactants are set according to the stoichiometric balance $\left(\mathrm{FF}_{\mathrm{MeOH}}=2 \mathrm{FF}_{\mathrm{AA}}\right)$, but methanol is in excess after combining the fresh feed with the recycle flow (stream 2 in Figures 4 and 5). For clarity, we define a parameter, feed ratio, as the ratio of pure methanol and pure acid, denoted as $F_{\mathrm{R}}=F_{\mathrm{MeOH}} / \mathrm{FF}_{\mathrm{AA}}$ hereafter. So, the following variables can be adjusted to meet design specifications: the heat inputs of four columns and the feed ratio $\left(F_{\mathrm{R}, \mathrm{A}}\right)$ in FSA, the reflux ratio (RR) of the RD, heat inputs of three columns, and the feed ratio $\left(F_{R, B}\right)$ in FSB. Here, the reflux ratio of the RD in FSB is kept constant in order to prevent the column from violating the temperature constraint for the catalyst. The thermal stability of commercial ion-exchange resin is $190{ }^{\circ} \mathrm{C}$ for the ion-exchange resin (Amberlyst 70). Increasing the reflux ratio (RR) of the column top causes the heavy key components' return; also, the temperature in the RD column will increase. Thus, the manipulated variable RR will be set to a proper value to prevent the column temperature from getting too high. Specifications for these two flowsheets (FSA and FSB) are the following: (I) Conversion of limiting reactant is greater or equal to $99 \%$. (II) The selectivity for the FSA should be greater than $98 \%$ and nearly $100 \%$ for the FSB. In terms of composition, the outlet concentration (from RD) of MMA is less than $1 \mathrm{~mol} \%$ for the FSA (stream 5 in Figure 4) and 1 ppm for the FSB (stream 5 in Figure 5). (III) Methanol in the stripper bottoms is kept below 1 mol \% (stream 7 in Figures 4 and 5). (IV) The water impurity in the bottoms of the dehydration column, FSA, is less than 1 mol \% (stream 10 of Figure 4).

In flowsheet $\mathrm{A}$, the heavy components (AA, MMA, DMA) tend to go out from the bottoms of the reactive stripper, and the purpose of the first two specifications (I and II) is to set a limit on undesired components in the separation section. Note that the different requirements on MMA in the second specification is due to the intrinsic property of boiling points. Again, even if we react away all the acid, the MMA becomes the heaviest component, and it can be produced using flowsheet A, without any specification on its concentration. Flowsheet B, on the other hand, gives an improved selectivity, if DMA is the major product. For a given production rate and product specifications, the following steps are adopted to obtain a near optimal design: (1) Guess the tray numbers in stripper in FSA $\left(N_{\mathrm{STR}, \mathrm{A}}\right)$ and FSB $\left(N_{\mathrm{STR}, \mathrm{B}}\right)$. (2) Guess the tray numbers of RD in stripping section in FSA $\left(N_{\mathrm{S}, \mathrm{A}}\right)$ and rectifying section in FSB $\left(N_{\mathrm{R}, \mathrm{B}}\right)$. (3) Guess the number of reactive trays $\left(N_{\mathrm{rxn}, \mathrm{A}}\right.$ and $\left.N_{\text {rxn,B }}\right)$. (4) Change the RD heat input, $F_{\mathrm{R}, \mathrm{A}}$, and stripper heat input in FSA to meet specifications I, II, and III, respectively. Similarly, change the stripper heat input and $F_{\mathrm{R}, \mathrm{B}}$ in $\mathrm{FSB}$ to meet specifications II and III, respectively. (5) Go back to step 3 and change $N_{\text {rxn,A }}$ and $N_{\text {rxn,B }}$ until the TAC is minimized. (6) Go back to step 2 and change $N_{\mathrm{S}, \mathrm{A}}$ and $N_{\mathrm{r}, \mathrm{B}}$ until the TAC is minimized. (7) Go back to step 1 and change $N_{\mathrm{STR}, \mathrm{A}}$ and $N_{\mathrm{STR}, \mathrm{B}}$ until the TAC is minimized. (8) Use heat input of the dehydration column to meet specification IV (for FSA) and change $N_{\text {DHC }}$ until the TAC is minimized. (9) Use heat inputs of the product column to meet the product specification, and change $N_{\text {PROD,A }}$ and $N_{\text {PROD,B }}$ until the TAC is minimized.

The TAC used to evaluate for the resultant design can be expressed as

$$
\mathrm{TAC}=\text { operating cost }+\frac{\text { capital cost }}{\text { payback year }}
$$

Here, the operating cost includes the costs of steam, cooling water, and catalyst, and capital cost covers the cost of columns, 
(a)

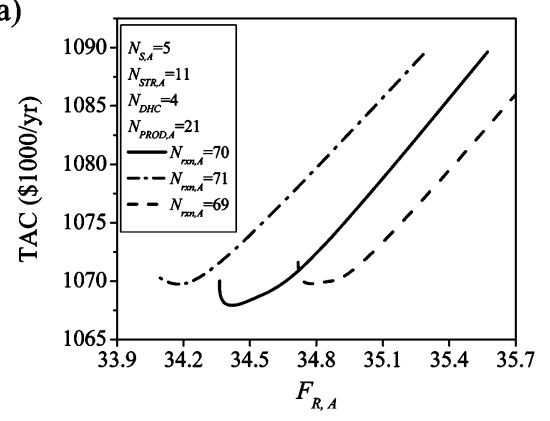

(b)

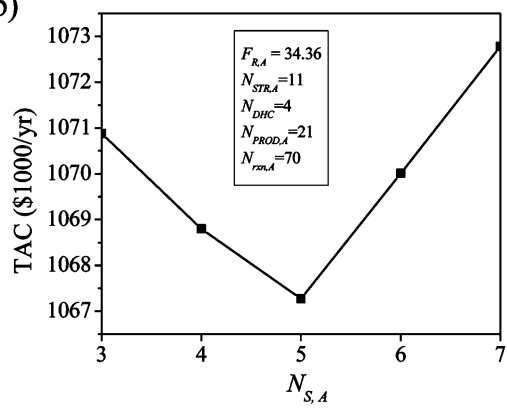

(d)

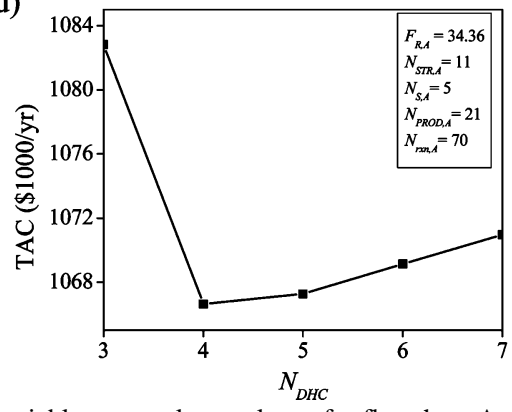

(c)

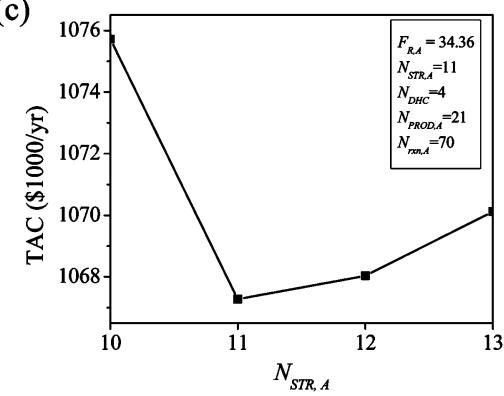

(e)

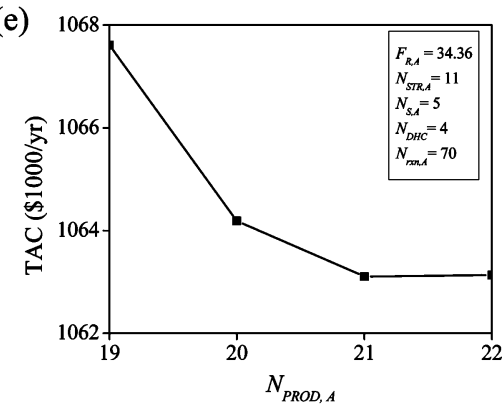

Figure 6. Effects of design variables on total annual cost for flowsheet A: (a) recycle ratio and number of reactive trays, (b) number of trays in the stripping section of the reactive stripper, (c) number of trays in the methanol recovery stripper, (d) number of trays in the dehydration column, and (e) number of trays in the product column.

Table 2. Stream Table of Flowsheet A for Adipic Acid Esterification

\begin{tabular}{|c|c|c|c|c|c|c|c|c|c|c|c|c|}
\hline stream number & 1 & 2 & 3 & 4 & 5 & 6 & 7 & 8 & 9 & 10 & 11 & 12 \\
\hline flow $(\mathrm{kmol} / \mathrm{h})$ & 20.0 & 394.5 & 10.0 & 250.47 & 154.87 & 124.1 & 30.76 & 15.76 & 20.04 & 10.72 & 0.75 & 9.96 \\
\hline $\begin{array}{l}\text { temperature } \\
(\mathrm{K})\end{array}$ & 356.4 & 357.6 & 453.15 & 339.9 & 356.3 & 339.9 & 369.8 & 318.1 & 318.1 & 511.4 & 538.8 & 509.0 \\
\hline pressure (atm) & 2.0 & 1.56 & 2.0 & 1.0 & 1.56 & 1.01 & 1.10 & 1.0 & 1.0 & 1.01 & 1.06 & 1.0 \\
\hline AA (mol frac) & 0 & 0.0001 & 1 & 0.0002 & 0.0006 & 0 & 0.0032 & 0.0050 & 0.0010 & 0.0074 & 0.1059 & $730 \mathrm{ppb}^{*}$ \\
\hline $\mathrm{MeOH}$ & 1 & 0.8711 & 0 & 0.8584 & 0.7029 & 0.8758 & 0.0050 & 0.0084 & 0.0076 & 0 & 0 & 0 \\
\hline MMA & 0 & 0.0005 & 0 & 0.0007 & 0.0050 & $8 \mathrm{ppb}$ & 0.0251 & 0.0488 & 0.0003 & 0.0717 & 0.8841 & 0.0099 \\
\hline water & 0 & 0.1237 & 0 & 0.1338 & 0.2271 & 0.1234 & 0.6453 & 0.2974 & 0.9904 & 0 & 0 & 0 \\
\hline DMA & 0 & 0.0045 & 0 & 0.0068 & 0.0643 & 0.0007 & 0.3212 & 0.6402 & 0.0006 & 0.9207 & 0.0099 & 0.9900 \\
\hline
\end{tabular}

* Parts per billion.

Table 3. Stream Table of the Flowsheet B for Adipic Acid Esterification

\begin{tabular}{|c|c|c|c|c|c|c|c|c|c|c|c|}
\hline stream number & 1 & 2 & 3 & 4 & 5 & 6 & 7 & 8 & 9 & 10 & 11 \\
\hline flow $(\mathrm{kmol} / \mathrm{h})$ & 20.0 & 169.14 & 10.0 & 24.42 & 179.13 & 149.14 & 29.98 & 3.58 & 13.6 & 20.0 & 9.99 \\
\hline temperature $(\mathrm{K})$ & 356.4 & 342.6 & 453.15 & 413.8 & 342.8 & 339.4 & 369.3 & 370.0 & 318.1 & 318.1 & 465.1 \\
\hline pressure (atm) & 2.0 & 1.2 & 2.0 & 1.1 & 1.0 & 1.0 & 1.10 & 1.1 & 1.0 & 1.00 & 1.1 \\
\hline AA (mol frac) & 0 & 0 & 1 & 0 & 0 & 0 & 0 & 0 & 0 & 0 & 0 \\
\hline $\mathrm{MeOH}$ & 1 & 0.9047 & 0 & 0.7426 & 0.7426 & 0.8919 & 99 ppm & 0.0004 & 10 ppm & 0.0015 & $43 \mathrm{ppb}^{* * *}$ \\
\hline MMA & 0 & 0 & 0 & 2 ppm* & $2 \mathrm{pm}$ & 0 & $10 \mathrm{ppb}$ & 0 & $21 \mathrm{ppb}$ & $2 \mathrm{ppb}$ & $16 \mathrm{ppb}$ \\
\hline water & 0 & 0.0948 & 0 & 0.2011 & 0.2011 & 0.1075 & 0.6667 & 0.9922 & 0.2692 & 0.9950 & 0.0096 \\
\hline DMA & 0 & 0.0005 & 0 & 0.0562 & 0.0562 & 0.0005 & 0.3333 & 0.0077 & 0.7307 & 0.0048 & 0.9903 \\
\hline
\end{tabular}

* Parts per million. ** Parts per billion.

trays, exchangers, and reboilers. A payback year of 3 is used here.

\section{Results and Discussion}

The results of the steady-state design of these two flowsheets are given in Table 1. Tables 2 and 3 give the stream tables.
Because both flowsheets are quite similar, here we show the figure of optimization in FSA. Figure 6 shows the different variables affect the TAC in FSA. The numbers of trays in the separation section of different columns have little impact on TAC values. Figure 6 a shows that $F_{\mathrm{R}, \mathrm{A}}$ has the greatest impact on TAC. Although the different feed ratio $\left(F_{\mathrm{R}, \mathrm{A}}\right)$ values could meet the same specification, we always find the lowest TAC 
(a)

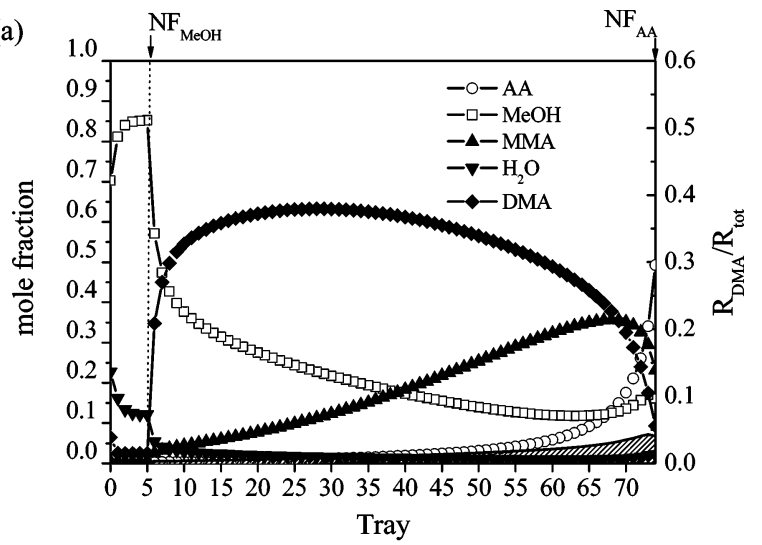

(b)

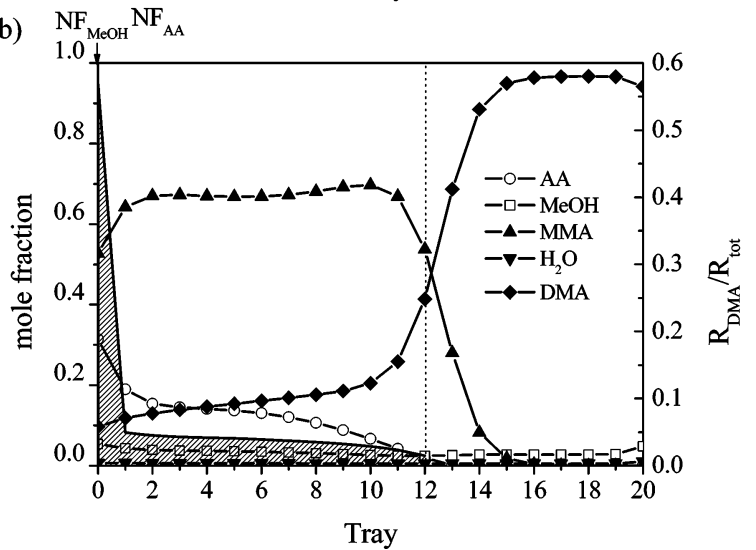

Figure 7. Composition profiles and fraction of total conversion (shaded area) in the reactive distillation column for flowsheet (a) A and (b) B.

for a specific value of $F_{\mathrm{R}, \mathrm{A}}$ (Figure 6a) using different numbers of reactive trays. The tradeoff comes from the competing costs for the reactive stripper and methanol recovery column. A larger recycle flow will increase the energy demand in the methanol recovery column while facilitating the reaction (as the result of higher light reactant concentration). The same observation also applies to FSB where a proper feed ratio is important to the design. The difference comes from the fact that flowsheet B has a greater advantage in terms of placement of the reactive zone, the relative position of product withdrawal, and the amount of catalyst loading. Thus, $F_{\mathrm{R}, \mathrm{B}}$ is less than half of the value of $F_{\mathrm{R}, \mathrm{A}}$. Figure 7 shows concentration profiles and the fraction of total conversion (to the major product) in the RD column for both flowsheets. The area with gray hatching shows the fraction of the total conversion that takes place on each tray. In Figure $7 \mathrm{~b}$, almost $50 \%$ of reaction takes place in the column base for FSB; the remaining $50 \%$ of reaction takes place in the column (note the tray numbers are counted from the bottom). Figure 7 a shows that although the reaction occurs anywhere in the entire reactive section, the bulk reaction still takes place in the upper section, where the concentration of the limiting reactant (adipic acid) is higher. Detailed comparisons of the TACs are given in Figure 8. The results show that the TAC of flowsheet A is $20 \%$ higher than that of flowsheet $\mathrm{B}$, in which the capital cost of FSA is $60 \%$ higher and the energy cost is $29 \%$ lower as compared to those of FSB. Figure $8 \mathrm{~b}$ reveals the costs of different process units for these two flowsheets.

\section{Extension to Dimethyl Glutarate}

Because of economic advantages, flowsheet B is adopted here for the two-stage esterification systems that have similar properties. In this section, we extend the process design to the production of dimethyl glutarate (DMG). The esterification of
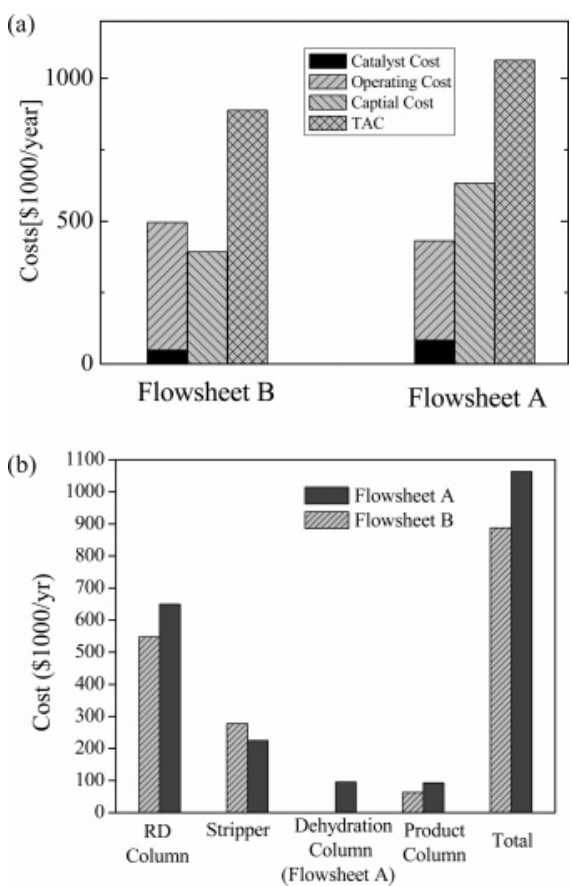

Figure 8. (a) TAC comparison for two different flowsheets and (b) cost breakdown for two different flowsheets.

glutaric acid $(\mathrm{GA})$ and methanol $(\mathrm{MeOH})$ proceeds by a twostage reversible reaction with glutaric acid monomethyl ester (monomethyl glutarate, MMG) as an intermediate:

$$
\begin{gathered}
\mathrm{GA}+\mathrm{MeOH} \underset{k_{-1}}{\stackrel{k_{1}}{\rightleftharpoons}} \mathrm{MMG}+\mathrm{H}_{2} \mathrm{O} \\
\mathrm{MMG}+\mathrm{MeOH} \underset{k_{-2}}{\stackrel{k_{2}}{\rightleftharpoons}} \mathrm{DMG}+\mathrm{H}_{2} \mathrm{O}
\end{gathered}
$$

Similar to the adipic acid esterification, the reaction rates can also be described by eq 2 . The rate constants shown below have a unit of $\mathrm{cm}^{6} / \mathrm{g}$ catalyst $/ \mathrm{min} / \mathrm{mol}$, taken from the work of Tsai. ${ }^{20}$

$$
\begin{aligned}
& k_{1}=3.346 \times 10^{7} \exp \left(\frac{-4417.4}{T}\right) \\
& k_{-1}=6.416 \times 10^{3} \exp \left(\frac{-84.5}{T}\right) \\
& k_{2}=3.487 \times 10^{5} \exp \left(\frac{-2042.2}{T}\right) \\
& k_{-2}=2.024 \times 10^{6} \exp \left(\frac{-4201.1}{T}\right)
\end{aligned}
$$

Again, the UNIFAC method was used to estimate all the NRTLHOC parameters. On the basis of the group contribution method and Aspen built-in data bank, the normal boiling points are ranked below in the descending order

$$
\begin{aligned}
& \mathrm{GA}\left(322.13{ }^{\circ} \mathrm{C}\right)>\mathrm{DMG}\left(197.12^{\circ} \mathrm{C}\right)> \\
& \operatorname{MMG}\left(172.28{ }^{\circ} \mathrm{C}\right)>\mathrm{H}_{2} \mathrm{O}\left(100.0{ }^{\circ} \mathrm{C}\right)> \\
& \mathrm{MeOH}\left(64.53{ }^{\circ} \mathrm{C}\right)
\end{aligned}
$$

This is a little different from the adipic acid system, because the boiling point of the major product, DMG, is higher than that of the byproduct, MMG. Similar to the adipic acid system, the two reactants still have the highest and lowest boiling points. 
(a)

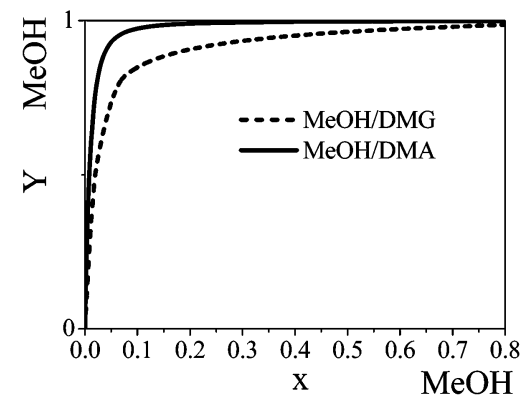

(b)

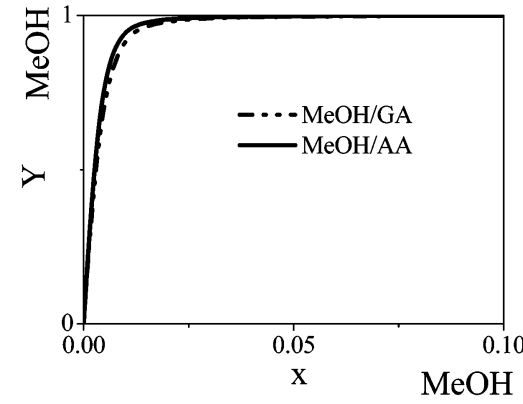

(c)

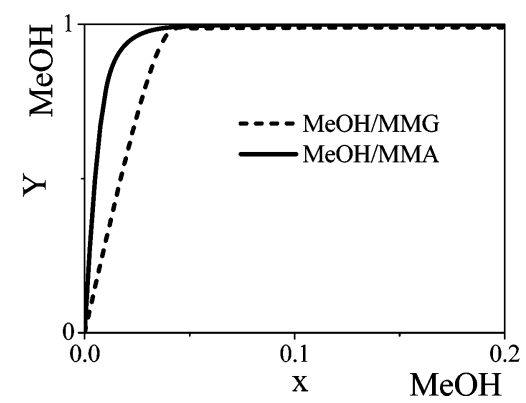

Figure 9. Comparisions with VLE diagrams for (a) dimethyl adipate and dimethyl glutarate + methanol, (b) dimethyl adipate and dimethyl glutarate + methanol, and (c) monomethyl adipate and monomethyl glutarate + methanol.

Before getting into the flowsheet generation, we examine the difference between the glutaric acid and adipic acid systems. The boiling point temperature difference between the excess reactant, methanol, and the product is $172{ }^{\circ} \mathrm{C}$ for the adipic acid system and $132{ }^{\circ} \mathrm{C}$ for the glutaric acid system. This implies that it is more difficult to separate methanol from the products for the glutaric system as compared to the adipic acid system (Figure 9a) while the boiling point difference is negligible for these two systems (Figure 9b). In terms of process design, that means that a distillation column will be more appropriate as compared to the stripper (Figure 5, T-701) for the glutaric system. Thus, a distillation column is used instead of a stripper (Figure 10, T-701).

The design steps are quite similar to those of DMA systems except for the methanol recovery column. The reflux ratio of the distillation column is used to prevent the product, DMG, from recycling back to the RD column, and the specification for the impurity is $1 \%$. After a sequential search, the best value of the feed ratio $\left(F_{\mathrm{MeOH}} / F_{\text {acid }}\right)$ for TAC minimization is found to be 6.1 (Figure 11a). Figure $11 \mathrm{~b}$ shows the TAC when the number of reactive trays is varied. In this process, we also consider the feed tray location of the recovery column $\left(\mathrm{NF}_{\mathrm{RC}}\right)$. Figure 11c shows the effect of a different number of trays in the rectifying section, and Figure 11d shows the TAC for the product column settings. The result of the steady-state design of the DMG system is given in the fourth column of Table 2. Table 4 lists all the stream information. Figure 12 shows the composition profile and the fraction of total conversion of the DMG system.

It is interesting to note that the TAC of the glutaric acid system is less than half of that of the adipic acid system. The energy cost ( $\$ 447000$ versus $\$ 129000$ ), especially in the reactive distillation reboiler duty ( 2199 and $717 \mathrm{~kW}$ ), accounts for $75 \%$ of the difference, and the remaining $25 \%$ comes from the capital cost (\$392000 versus \$275000). The reason for that is the significantly different rate constant. For example, rate constants at $180{ }^{\circ} \mathrm{C}$ for these two systems are

$$
\begin{gathered}
\text { adipic acid: } k_{1} / k_{-1} / k_{2} / k_{-2}=692 / 695 / 191 / 74 \\
\text { glutaric acid: } k_{1} / k_{-1} / k_{2} / k_{-2}=1954 / 5325 / 3848 / 3670
\end{gathered}
$$

The forward reaction rate for the glutaric acid esterification is 3-20 times faster than that of the adipic acid system, and moreover, the second stage reaction of the gultaric acid system is twice as fast as the first stage reaction. Therefore, a much lower monoester concentration is observed in the DMG system (Figure 12) as compared to that of the DMA system (Figure $7 b)$. It should be noticed here that the equilibrium constants $\left(K_{1, \text { eq }}\right.$ and $\left.K_{2 \text {,eq }}\right)$ for the adipic acid are 2-3 times larger than those of the glutaric acid system, but this difference does not impose difficulty for reactive distillation with multistage reaction/separation capability. Despite the fact that the boiling point ranking of the adipic acid is favorable for improved selectivity

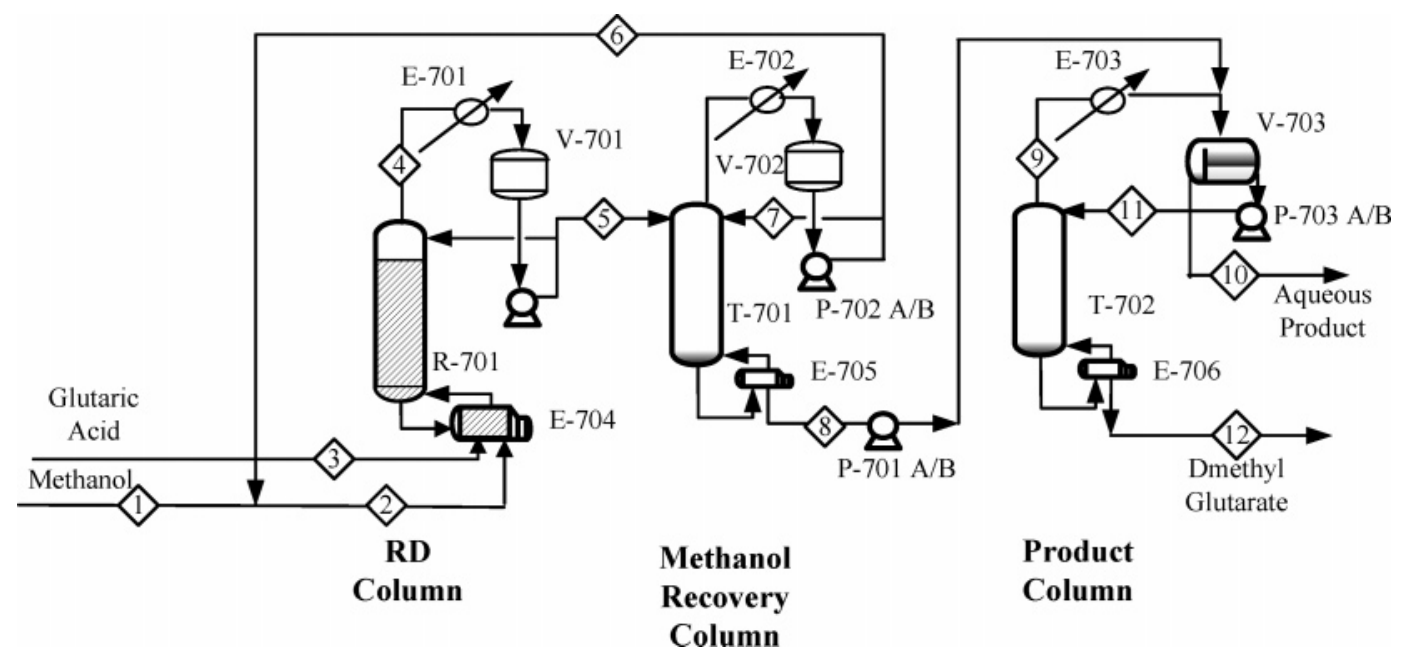

Figure 10. Flowsheet for dimethyl glutarate production. 
(a)

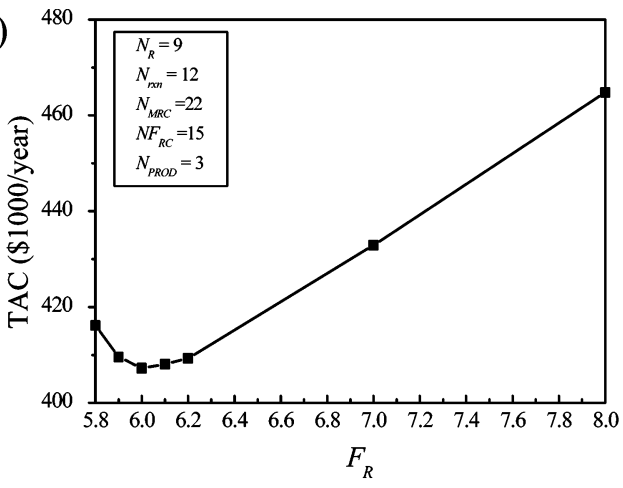

(c)

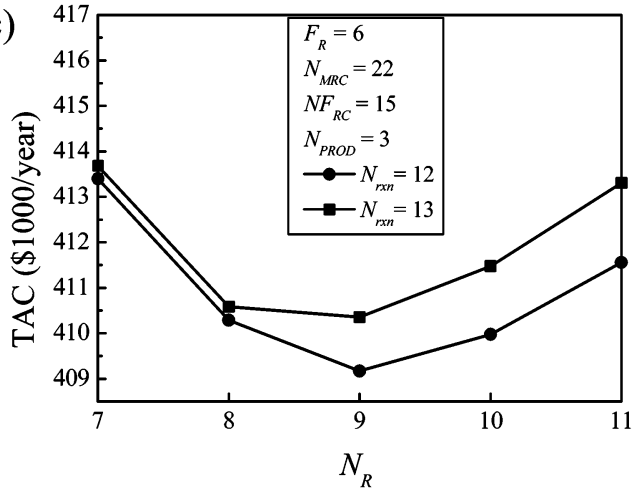

(b)

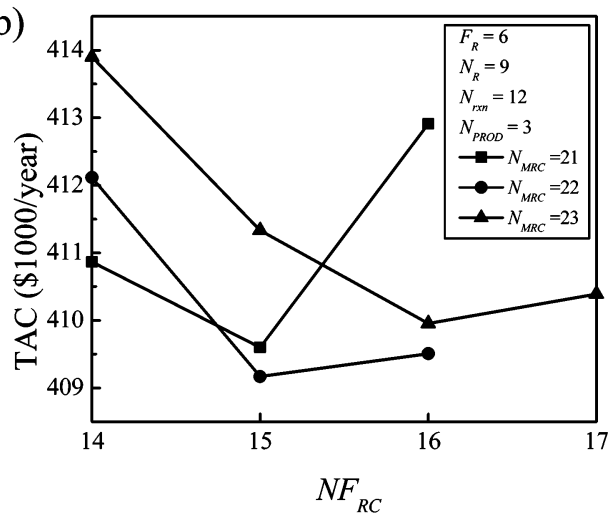

(d)

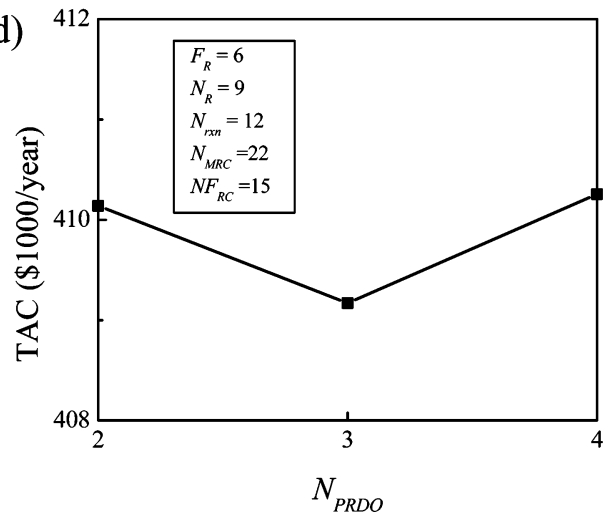

Figure 11. Effects of design variables on total annual cost: (a) recycle ratio, (b) feed tray location and number of trays in the methanol recovery column, (c) number of trays in the rectifying section and number of reactive trays of the reactive distillation column, and (d) number of trays in the product column.

Table 4. Stream Table for Glutaric Acid Esterification

\begin{tabular}{|c|c|c|c|c|c|c|c|c|c|c|c|c|}
\hline stream number & 1 & 2 & 3 & 4 & 5 & 6 & 7 & 8 & 9 & 10 & 11 & 12 \\
\hline flow $(\mathrm{kmol} / \mathrm{h})$ & 20.0 & 63.44 & 10.0 & 7.77 & 73.44 & 43.44 & 31.28 & 30.0 & 7.75 & 19.97 & 17.78 & 10.03 \\
\hline temperature $(\mathrm{K})$ & 356.4 & 347.8 & 351.2 & 352.8 & 356.3 & 343.6 & 343.6 & 376.3 & 372.3 & 323.15 & 323.15 & 463.7 \\
\hline pressure (atm) & 2.0 & 1.5 & 2.0 & 1.2 & 1.56 & 1.2 & 1.2 & 1.3 & 1.1 & 1.0 & 1.0 & 1.1 \\
\hline AA (mol frac) & 0 & 0 & 1 & 0 & 0 & 0 & 0 & 0 & 0 & 0 & 0 & 0 \\
\hline $\mathrm{MeOH}$ & 1 & 0.9455 & 0 & 0.5445 & 0.5445 & 0.9205 & 0.9205 & $100 \mathrm{ppm}$ & 0.0006 & 0.0001 & 0.0003 & $6 \mathrm{ppm}$ \\
\hline MMA & 0 & 0 & 0 & 0 & 0 & 0 & 0 & $2 \mathrm{ppb}$ & 0 & 0 & $4 \mathrm{ppb}$ & $7 \mathrm{ppb}$ \\
\hline water & 0 & 0.0543 & 0 & 0.3192 & 0.3192 & 0.0793 & 0.0793 & 0.6667 & 0.9311 & 0.9963 & 0.4159 & 0.0099 \\
\hline DMA & 0 & 688 ppm* & 0 & 0.1362 & 0.1362 & $99 \mathrm{ppm}$ & 99 ppm & 0.3333 & 0.0629 & 0.0035 & 0.5838 & 0.9900 \\
\hline
\end{tabular}

* Parts per million.

(compared to glutaric system), the reaction kinetics dominates the outcomes of process design, as the result of the order of magnitude difference. The comparison made here illustrates the importance of absolute rate constant to the cost of reactive distillation systems.

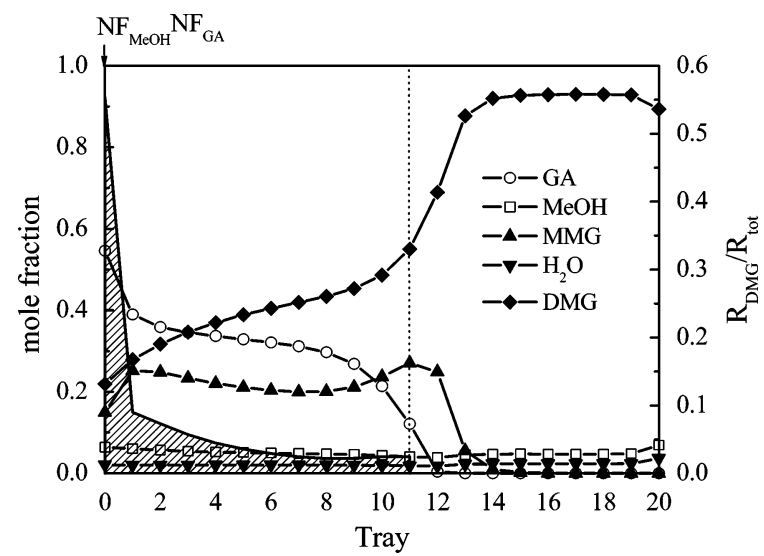

Figure 12. Composition profiles and fraction of total conversion (shaded area) in the reactive distillation column for gultaric acid esterification.

\section{Conclusion}

This paper proposes conceptual designs for the reactive distillation processes for adipic acid esterification, a two-stage reversible reaction. Provided with experimental data on vapor pressure and UNIFAC method estimated NRTL parameters, the NTRL-HOC model provides a reasonably good description of phase equilibria. Two possible process flowsheets are generated at the conceptual design level. A systematic design procedure is presented to improve the quantitative design based on the total annual cost (TAC). Similarities and differences of these two flowsheets are explored, and explanations of the different economical potentials are given. Results show that both plantwide flowsheets need a large recycle ratio for the light reactant and high purity diesters can be produced. Because of unfavorable boiling point ranking (the reactants being the lightest and heaviest) and the "excess-reactant" operation, relatively, the TACs are much higher as compared to the cases for singlestage acetic acid esterification. ${ }^{8}$ The approach can be extended to the glutaric acid esterification with little modification. Appendix

Model parameters used in vapor pressure, VLE, and VLLE computation for adipic acid and glutaric esterification systems appear in Tables 5-8. 


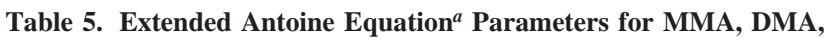
MMG, and DMG

\begin{tabular}{lllllr}
\hline component & \multicolumn{1}{c}{$C_{1}$} & \multicolumn{1}{c}{$C_{2}$} & $C_{3}$ & $C_{4}$ & \multicolumn{1}{c}{$C_{5}$} \\
\hline MMA & -4503.023 & 103889.81 & 0.000 & 1.314 & 794.908 \\
DMA & 1139.710 & -39383.491 & 0.000 & 0.285 & -192.449 \\
MMG & -8555.6 & $1.827 \times 10^{6}$ & 0.000 & 10.00 & 0.000 \\
DMG & $-5.505 \times 10^{5}$ & $1.739 \times 10^{7}$ & 0.000 & -128.16 & 93139.4 \\
$\quad a \ln P(\mathrm{kPa})=C_{1}+C_{2} /\left(T(\mathrm{~K})+C_{3}\right)+C_{4} T(\mathrm{~K})+C_{5} \ln T(\mathrm{~K})$.
\end{tabular}

Table 6. NRTL ${ }^{a}$ Binary Parameters in DMA System

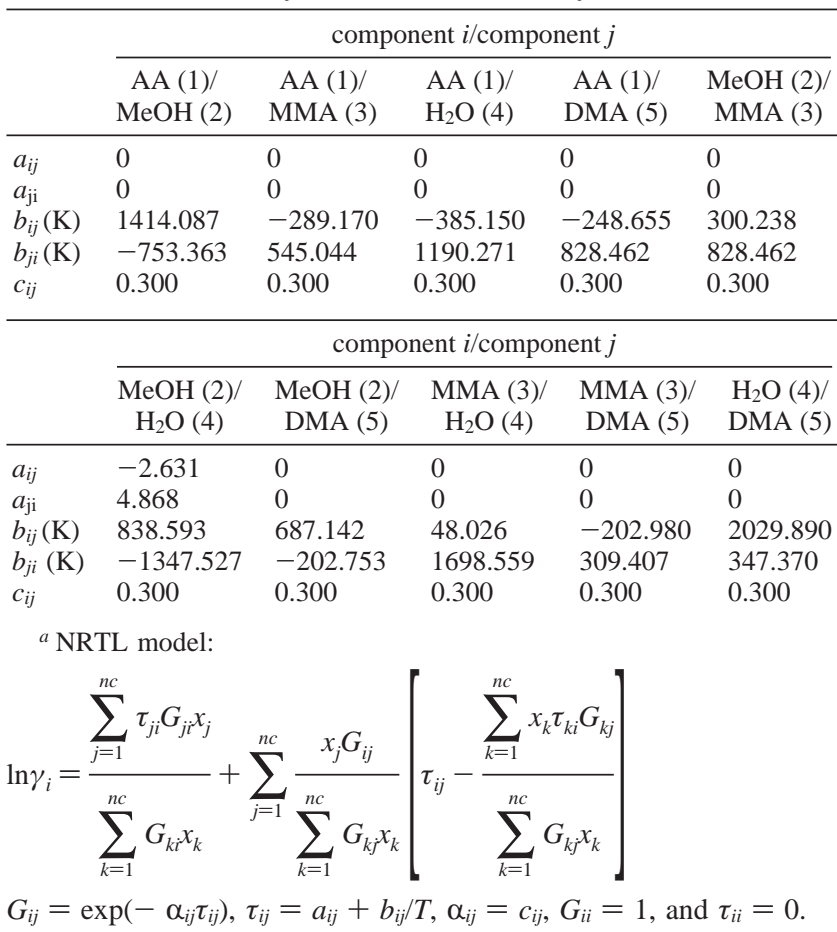

Table 7. NRTL ${ }^{a}$ Binary Parameters in DMG System

\begin{tabular}{|c|c|c|c|c|c|}
\hline & \multicolumn{5}{|c|}{ component $i /$ component $j$} \\
\hline & $\begin{array}{c}\mathrm{GA}(1) / \\
\mathrm{MeOH}(2)\end{array}$ & $\begin{array}{c}\text { GA (1)/ } \\
\text { MMG (3) }\end{array}$ & $\begin{array}{l}\mathrm{GA}(1) / \\
\mathrm{H}_{2} \mathrm{O}(4)\end{array}$ & $\begin{array}{c}\text { GA (1)/ } \\
\text { DMG (5) }\end{array}$ & $\begin{array}{c}\mathrm{MeOH}(2) / \\
\mathrm{MMG}(3)\end{array}$ \\
\hline$a_{i j}$ & 0 & 0 & 0 & 0 & 0 \\
\hline$a_{\mathrm{ji}}$ & 0 & 0 & 0 & 0 & 0 \\
\hline$b_{i j}(\mathrm{~K})$ & 1322.396 & -381.653 & -319.111 & 901.943 & 306.376 \\
\hline$b_{j i}(\mathrm{~K})$ & -708.714 & 1029.585 & 1010.599 & -459.037 & -17.346 \\
\hline \multirow[t]{3}{*}{$c_{i j}$} & 0.300 & 0.300 & 0.300 & 0.300 & 0.300 \\
\hline & \multicolumn{5}{|c|}{ component $i /$ component $j$} \\
\hline & $\begin{array}{c}\mathrm{MeOH}(2) / \\
\mathrm{H}_{2} \mathrm{O}(4)\end{array}$ & $\begin{array}{c}\mathrm{MeOH}(2) / \\
\mathrm{DMG}(5)\end{array}$ & $\begin{array}{c}\text { MMG (3)/ } \\
\mathrm{H}_{2} \mathrm{O} \text { (4) }\end{array}$ & $\begin{array}{l}\text { MMG (3)/ } \\
\text { DMG (5) }\end{array}$ & $\begin{array}{l}\mathrm{H}_{2} \mathrm{O}(4) / \\
\mathrm{DMG}(5)\end{array}$ \\
\hline$a_{i j}$ & -2.631 & 0 & 0 & 0 & 0 \\
\hline & 4.868 & 0 & 0 & 0 & 0 \\
\hline$b_{i j}(\mathrm{~K})$ & 838.593 & 618.625 & 129.261 & 422.576 & 1698.556 \\
\hline$b_{j i}(\mathrm{~K})$ & -1347.527 & -334.455 & 1423.055 & -216.035 & 48.026 \\
\hline$c_{i j}$ & 0.300 & 0.300 & 0.300 & 0.300 & 0.300 \\
\hline
\end{tabular}

${ }^{a}$ NRTL model:

$\left.\ln \gamma_{i}=\frac{\sum_{j=1}^{n c} \tau_{j i} G_{j i} x_{j}}{\sum_{k=1}^{n c} G_{k i} x_{k}}+\sum_{j=1}^{n c} \frac{x_{j} G_{i j}}{\sum_{k=1}^{n c} G_{k j} x_{k}} \tau_{i j}-\frac{\sum_{k=1}^{n c} x_{k} \tau_{k i} G_{k j}}{\sum_{k=1}^{n c} G_{k j} x_{k}}\right\rfloor$
$G_{i j}=\exp \left(-\alpha_{i j} \tau_{i j}\right), \tau_{i j}=a_{i j}+b_{i j} / T, \alpha_{i j}=c_{i j}, G_{i i}=1$, and $\tau_{i i}=0$.
Table 8. NRTL ${ }^{a}$ Binary Parameters in DMA System (Use for LLE Calculation)

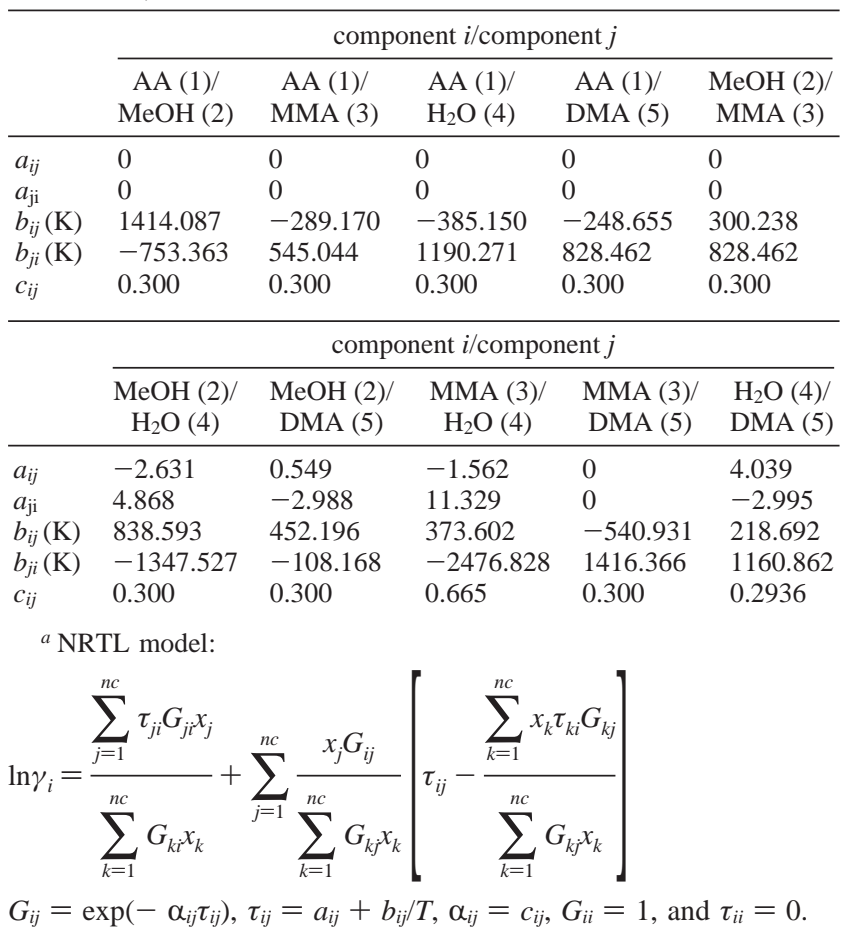

\section{Nomenclature}

$\mathrm{AA}=$ adipic acid

$C_{i}=$ concentration of component $i$

$\mathrm{DBE}=$ dibasic ester

DMA $=$ dimethyl adipate

DMG $=$ dimethyl glutarate

DMS = dimethyl succinate

$F_{\mathrm{AA}}=$ adipic acid flow rates

$F_{\mathrm{MeOH}}=$ methanol flow rates

$\mathrm{FF}_{\mathrm{AA}}=$ adipic acid feed flow rates

$\mathrm{FF}_{\mathrm{MeOH}}=$ methanol feed flow rates

$F_{\mathrm{R}}=$ feed ratio

$\mathrm{FSA}=$ flowsheet $\mathrm{A}$

$\mathrm{FSB}=$ flowsheet $\mathrm{B}$

$\mathrm{GA}=$ glutaric acid

$\mathrm{HK}=$ heavy key component

HHK $=$ heavier than heavy key component

$k=$ rate constant

$K_{\text {eq }}=$ equilibrium constant

$\mathrm{LK}=$ light key component

LLK = lighter than light key component

$\mathrm{MeOH}=$ methanol

MMA = monomethyl adipate

$\mathrm{MMG}=$ monomethyl glutarate

$\mathrm{MRC}=$ methanol recovery column

$N_{\text {DHC }}=$ number of trays in dehydration column

$\mathrm{NF}_{\mathrm{RC}}=$ feed tray location of methanol recovery column

$N_{\text {PROD }}=$ number of trays in product column

$N_{\mathrm{R}}=$ number of trays in rectifying section

$N_{\text {MRC }}=$ number of trays in methanol recovery column

$N_{\text {rxn }}=$ number of trays in reactive section

$N_{\mathrm{S}}=$ number of trays in the stripping section

$N_{\mathrm{STR}}=$ number of trays in stripper

$\mathrm{RC}=$ methanol recovery column

$\mathrm{RDC}=$ reactive distillation column

$\mathrm{RR}=$ reflux ratio

$\mathrm{TAC}=$ total annual cost 
$X_{\mathrm{aq}}=$ liquid mole fraction in aqueous phase

$X_{\mathrm{PROD}}=$ liquid mole fraction in product stream

\section{Acknowledgment}

This work was supported by the Ministry of Economic Affairs under grant 92-EC-17-A-09-S1-019 and National Taiwan University under the Excellence Research Program.

\section{Literature Cited}

(1) Doherty, M. F.; Malone, M. F. Conceptual Design of Distillation Systems; McGraw-Hill: New York, 2001.

(2) Sundmacher, K.; Kienle, A. Reactive Distillation: Status and Future Directions; Wiley: Weinheim, 2003.

(3) Taylor, R.; Krishna, R. Modelling Reactive Distillation. Chem. Eng. Sci. 2000, 55, 5183.

(4) Agreda, V. H.; Partin, L. R.; Heise, W. H. High Purity Methyl Acetate via Reactive Distillation. Chem. Eng. Prog. 1990, 86, 40.

(5) Kenig, E. Y.; Bader, H.; Gorak, A.; Bessling, B.; Adrian, T.; Schoenmakers, H. Investigation of Ethyl Acetate Reactive Distillation Process. Chem. Eng. Sci. 2001, 56, 6185.

(6) Hanika, J.; Kolena, J.; Smejkal, Q. Butyl Acetate via Reactive Distillation-Modelling and Experiment. Chem. Eng. Sci. 1999, 54, 5202.

(7) Gangadwala, J.; Kienle, A.; Stein, E.; Mahajani, S. Production of Butyl Acetate by Catalytic Distillation: Process Design Studies. Ind. Eng. Chem. Res. 2004, 43, 136.

(8) Tang, Y. T.; Chen, Y. W.; Huang, H. P.; Yu, C. C.; Hung, S. B.; Lee, M. J. Design of Reactive Distillations for Acetic Acid Esterification. AIChE J. 2005, 51, 1683.

(9) Jacobs, R.; Krishna, R. Multiple Solutions in Reactive Distillation for Methyl Tert-Butyl Ethers Synthesis. Ind. Eng. Chem. Res. 1993, 32, 1706.

(10) Sundmacher, K.; Hoffmann, U. Multiple Reactions in Catalytic Distillation Processes for the Production of the Fuel Oxygenates MTBE and TAME: Analysis by Rigorous Model and Experimental Validation. Chem. Eng. Sci. 1999, 54, 2839.

(11) Ung, S.; Doherty, M. F. Synthesis of Reactive Distillation Systems with Multiple Equilibrium Chemical Reactions. Ind. Eng. Chem. Res. 1995 $34,2555$.

(12) Ung, S.; Doherty, M. F. Vapor-Liquid Phase Equilibrium in Systems with Multiple Chemical Reactions. Chem. Eng. Sci. 1995, 50, 23.

(13) Luo, H. P.; Xiao, W. D. A Reactive Distillation Process for a Cascade and Azeotropic Reaction System: Carbonylation of Ethanol with Dimethyl Carbonate. Chem. Eng. Sci. 2001, 56, 403.

(14) Chan, K. W. Kinetic Behavior of Heterogeneous Esterification of Adipic Acid with Methanol. M.S. Thesis, National Taiwan University of Science and Technology, Taipei, Taiwan, 2004.

(15) Lee, M. J.; Lai, C. H.; Wang, Z. B.; Lin, H. M. Vapor-Liquid Equilibrium of Mixtures Containing Adipic Acid, Glutaric Acid, Dimethyl Adipate, Dimethyl Glutarate, Methanol, and Water. J. Chem. Eng. Data 2007, 52, 1291.

(16) Hayden, J. G.; O'Connell, J. P. A Generalized Method for Predicting Second Virial Coefficients. Ind. Eng. Chem. Process Des. Dev. 1975, 14, 209.

(17) Fredenslund, A.; Gmehling, J.; Rasmussen, P. Vapor-Liquid Equilibria Using UNIFAC: A Group-Contribution Method; Elsevier: Amsterdam, 1977.

(18) Hung, S. B.; Lin, H. M.; Yu, C. C.; Huang, H. P.; Lee, M. J. Liquid-Liquid Equilibria of Aqueous Mixtures Containing Selected Dibasic Esters and/or Methanol. Fluid Phase Equilib. 2006, 248, 174.

(19) Tung, S. J.; Yu, C. C. Effects of Relative Volatility Ranking to the Design of Reactive Distillation. AIChE J. 2007, 53, 1278.

(20) Tsai, Y. T. Kinetic Behavior of Heterogeneous Esterification of Glutaric Acid with Methanol. M.S. Thesis, National Taiwan University of Science and Technology, Taipei, Taiwan, 2005.

Received for review April 29, 2007 Revised manuscript received February 1, 2008 Accepted February 7, 2008

IE070609+ 